\title{
O neopragmatismo de Richard Rorty e a reflexão política contemporânea
}

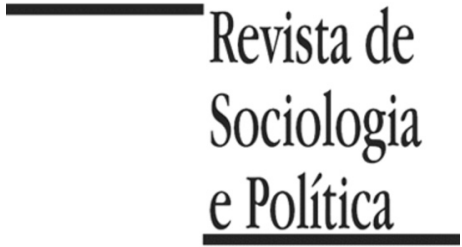

\author{
Sérgio Eduardo Ferraz
}

\section{RESUMO}

Este artigo examina o pensamento filosófico de Richard Rorty e, em particular, sua dimensão política, delineando seu tratamento original e crítico de temas centrais à teoria política contemporânea. O objetivo do texto é triplo: chamar a atenção para a fertilidade das ideias de um autor ainda pouco lido no Brasil (i), assinalar as notáveis consequências corrosivas da abordagem rortyana para pressupostos e pretensões fundantes de importantes vertentes da teoria política (ii), e, numa ótica mais positiva, apontar o potencial inspirador dos escritos desse autor para a reflexão sobre novos modos de justificação da democracia (iii). Salientam-se também, nesse último caso, os limites impostos a esse tipo de empreitada político-intelectual. A abordagem empregada consiste em demarcar os contornos gerais do projeto filosófico do autor, seguindo-se uma apresentação dos tópicos mais propriamente políticos da obra de Rorty. Mais especificamente, o artigo explora a proposta rortyana de substituição da noção de verdade pela de justificação, assinalando-se suas consequências para pretensões de verdade, objetividade e universalismo, presentes em diversas linhas da teoria política. Nesse veio, o artigo discute as eventuais implicações relativistas das teses rortyanas, chegando-se, por essa rota, às ideias de contingência, imaginação e persuasão, núcleos conceituais vitais à reflexão em tela. Um breve contraste com posições de autores como Habermas e Rawls, caros ao próprio Rorty, é esboçado no propósito de tornar mais clara a especificidade da abordagem rortyana da política. Transitando, do modo assinalado, por esses tópicos, o texto resulta em um panorama sintético da perspectiva rortyana acerca do que vem a ser, contemporaneamente, uma "política democrática", liberta de "universalismos" e "objetividades", na qual ganham estatuto decisivo questões de justificação, tolerância e coexistência, necessariamente pensadas enquanto construtos culturais contingentes, no âmbito interno de sociedades democráticas e no plano global (onde vigoram regimes políticos assentados em valores políticos distintos e mesmo contraditórios). Desse modo, o texto busca fornecer ao leitor uma introdução e uma amostra das dimensões críticas e construtivas presentes na obra de Rorty, apostando que agendas de pesquisa preocupadas com a temática da justificação ético-normativa da democracia e com os limites da própria tolerância democrática encontrem nesse autor uma fonte fecunda de inspiração.

PALAVRAS-CHAVE: teoria política contemporânea; neopragmatismo; democracia; justificação; limites da tolerância

Recebido em 26 de Julho de 2012. Aprovado em 6 de Novembro de 2012.

\section{Introdução: Rorty. uma primeira aproximação ${ }^{1}$}

${ }^{1}$ Agradeço aos comentários dos pareceristas anônimos da Revista de Sociologia e Política. Eventuais imprecisões são, naturalmente, de minha inteira responsabilidade.
$\mathrm{E}$ ste artigo tem por objetivo o exame de aspectos do pensamento filosófico de Richard Rorty e, em especial, a apreciação de suas implicações frente a um eixo de temas relevantes para a teoria política contemporânea. Mais especificamente, o trabalho propõe-se a explorar o neopragmatismo rortyano e a examinar suas contribuições para problemas associados à compreensão das noções de verdade, justificação, objetividade, universalismo e progresso moral.

Grosso modo, a obra de Rorty pode ser entendida como centrada em dois horizontes complementares: de um lado, a crítica sistemática à reflexão filosófica tradicional, que fez do exame das condições do conhecimento o seu norte central; de outro, o esforço de contribuir para o esboço de um novo projeto filosófico ou, mais exatamente, de uma nova cultura intelectual. O que estaria em jogo, em uma das leituras possíveis do empreendimento rortyano, seria a 
${ }^{2}$ Se a esse conjunto de autores Rorty associa a inspiração dos fins que presidem seu esforço intelectual, é em outro conjunto de filósofos - vinculados à tradição analítica - que ele encontrará os meios para viabilizar sua empresa: trata-se aqui de nomes como Quine, Sellars, Davidson, Ryle, Kuhn e Putnam (Rorty 1988, p. 18). radicalização e o aprofundamento do próprio projeto iluminista, libertando-o de suas últimas amarras metafísicas. A bagagem intelectual herdada que the oferece suporte nessa empreitada é o resultado da combinação singular de tradições bem distintas: o pragmatismo clássico norte-americano - com especial atenção para William James e John Dewey - e certa vertente da filosofia europeia continental que tem em Nietzsche, Wittgenstein e Heiddeger seus principais expoentes ${ }^{2}$. É da junção e da transformação desses veios heterogêneos de pensamento que Rorty constrói sua arquitetura de ideias a um tempo extremamente original, provocativa e polêmica.

Para fins do presente texto, o exame da obra de Rorty é tomado como um meio privilegiado de propor uma reflexão produtiva sobre temas atuais no cenário da teoria política contemporânea, particularmente no que se refere às suas correntes vinculadas a um horizonte normativo e ético. Nesse sentido, parece estimulante trazer à discussão as ideias rortyanas sobre o estatuto da verdade e da justificação, no propósito de ajudar a pensar o problema perene das fundações e dos alicerces da reflexão política. Da mesma forma, acreditase ser de utilidade para a pesquisa contemporânea o estudo das formas de tratamento que Rorty sugere às pretensões de universalidade no debate normativo, incluídas aqui as questões relativas às diferenças culturais e ao diálogo entre sociedades vinculadas a valores e crenças distintas. Trata-se, aqui, de imaginar, a partir de sugestões avançadas por Rorty, em que pode consistir, no plano global, a noção de progresso moral e de uma política democrática ampliada, desafios que ganham em premência quando consideramos a aceleração dos processos que tornam mais e mais interdependentes as diversas sociedades.

Na medida em que percorre esse conjunto de questões presentes na obra rortyana, o texto mostra outra importante dimensão contida no pensamento do autor em tela, a saber, a preocupação reiterada de levantar indagações acerca da própria natureza do empreendimento da Filosofia Política e de seus modos de validação. Também nessa matéria, a provocação rortyana em defesa de justificações localizadas e provincianas pode estimular uma reflexão útil.

O artigo está organizado da seguinte forma. Após essa parte introdutória, a seção subsequente (II) esboça, em linhas gerais, o projeto filosófico de Rorty, mostrando suas ambições, algumas ideias-reguladoras gerais, coerentemente presentes nos escritos desse autor, e as principais influências que sofreu. A terceira seção (III), a principal do artigo, cuida de sistematizar as principais ideias políticas do autor em foco, centrando-se no seu projeto de "política democrática", opção que permite explorar um leque temático de interesse para a reflexão ético-normativa contemporânea. Inicialmente, examina-se a proposta rortyana de substituir, no espaço da política, a noção de verdade pela de justificação. Sendo este último conceito estruturado de um modo deliberadamente "local" e "contextual", mostram-se, em seguida, as implicações do ponto para as ideias de objetividade e universalismo. Discutem-se, em seguida, as consequências "relativistas" das teses rortyanas, aspecto sublinhado pelos seus críticos, chegando-se, por essa via, às ideias de contingência, imaginação e persuasão, outros núcleos conceituais centrais à reflexão em tela. Por fim, breve contraste com posições de autores como Habermas e Rawls é esboçado no propósito de tornar mais clara a perspectiva rortyana. Ao longo do trabalho, sugere-se que agendas de pesquisas inspiradas pelo pensamento rortyano podem contribuir para delimitar com mais nitidez o terreno normativo das fundações ou justificativas associadas à democracia bem como iluminar as 


\section{Rorty: o projeto filosófico}

${ }^{3}$ A referência a levar às últimas consequências o empreendimento iluminista pode soar surpreendente ou mesmo desconcertante para os que enxergam em Rorty um irracionalista pós-moderno. Para sustentar a perspectiva do texto, o texto lastreia-se em Robert B. Brandom, editor de Rorty and His Critics (Brandom 2000). $\mathrm{Na}$ introdução a esse volume, Brandom desenvolve a ideia da existência, na obra rortyana, de uma analogia entre autoridade moral externa (Deus, o direito natural, uma ordem objetiva de valores independente da vontade dos homens, etc.) e autoridade cognitiva externa (a ideia de uma realidade objetiva construída previamente e de modo independente em relação às práticas humanas, constituindo o padrão para as pretensões de verdade dessas últimas). Com o Iluminismo, os homens teriam eliminado a primeira das duas autoridades, restando ainda por realizar o acerto de contas com a segunda. Em decorrência, a filosofia de Rorty encontraria aqui seu propósito último (idem, p. xi-xii; Crisóstomo de Souza 2005, p. 24). Pode-se dizer também que Rorty é profundamente ligado à boa parte da herança iluminista, em termos das suas principais instituições e práticas, como a democracia e os valores ligados à tolerância, justiça e solidariedade, rejeitando, porém, decididamente, as suas justificações filosóficas vinculadas à noção de uma razão universalista e objetiva (Rorty 1993, p. 121; possibilidades e os limites de um diálogo entre sociedades comprometidas com diferentes valores políticos e morais.

Esta seção apresenta um esboço do empreendimento filosófico rortyano. Para isso, destacam-se os contornos básicos de sua arquitetura argumentativa abrindo caminho para, em seguida, na parte subsequente, apontar e explorar as principais ideias especificamente políticas presentes na concepção em foco.

Uma maneira de aproximar-se da obra de Rorty é discernir, no seu interior, um eixo duplo de propósitos complementares, a saber, uma tarefa crítica de rejeição a uma forma tradicional de reflexão filosófica, vista como algo a ser superado, associada à construção de um conjunto de proposições voltado para o desenho de um novo projeto filosófico ou, mais exatamente, de uma nova cultura intelectual (Rorty 1982, p. 40-46; Brandom 2000, p. X-XIII; Ramberg 2007). Esse novo projeto é encarado por Rorty como uma maneira de levar às últimas consequências o próprio empreendimento iluminista ${ }^{3}$, mediante o aprofundamento das rupturas inovadoras produzidas por seus "heróis" filosóficos particulares, uma galeria composta pelos pragmatistas norte-americanos clássicos - particularmente, William James e John Dewey - e por expoentes da filosofia europeia como Nietzsche, Wittgenstein e Heiddeger (Rorty 1988, p. 16-18; 1982, p. 231-238; 1993, p. 119-121; Brandom 2000, p. xi-xii) ${ }^{4}$.

Na introdução à Filosofia e o Espelho da Natureza (RORTY, 1988, p. 1522), uma das suas obras mais importantes, Rorty nos dá uma breve síntese de suas metas intelectuais. Visita-se esse texto como primeiro passo que viabiliza um posterior detalhamento de um arco coerente de tópicos e questões recorrentes nos escritos desse autor.

No livro em questão, Rorty delineia o que seria a autoimagem tradicional da reflexão filosófica. Seus cultores tenderiam a vê-la como centrada em problemas permanentes, transcendentes de contextos históricos particulares, adquirindo especial saliência a temática do conhecimento e da mente. A filosofia cuidaria, mais exatamente, dos fundamentos ou das fundações do conhecimento, entendido o processo cognitivo como representação do que nos é exterior. Nas palavras do próprio Rorty,

conhecer é representar cuidadosamente o que é exterior à mente; portanto, compreender a possibilidade e natureza do conhecimento é compreender o modo pelo qual a mente se torna apta a construir tais representações (idem, p. 15).

Munida de tal saber sobre os fundamentos do conhecimento, a Filosofia pode reivindicar uma posição notavelmente especial frente ao resto da cultura: se a esta caberia articular as diferentes pretensões de conhecimento, ao empreendimento filosófico, senhor dos alicerces da operação cognitiva, cumpriria examiná-las e julgá-las. A Filosofia, consequentemente, emerge como um tribunal da razão, "sustentando ou negando as pretensões do resto da cultura" (idem, p. 16), ao distinguir as áreas bem sucedidas na operação de representação das demais. No núcleo desse edifício que sustenta a autoimagem tradicional da reflexão filosófica aparece, no período moderno, para Rorty, a sequência Descartes-Locke-Kant, responsável pela inserção da Filosofia nesse lugar privilegiado.

Em que pese as incessantes mutações do cenário intelectual e cultural, essa forma tradicional de compreender seu empreendimento continuou solidamente 
1998, p. 124; Crisóstomo de Souza 2005, p. 23).

${ }^{4}$ Tanto Robert B. Brandom como Bjorn Ramberg consideram que o vocabulário que Rorty emprega para levar adiante a sua versão própria do pragmatismo vem a ser uma combinação entre o naturalismo e o historicismo. Brandom sustenta que o primeiro desses dois termos possui certa posição privilegiada no projeto rortyano (Brandom 2000, p. xiv).

${ }^{5}$ Um excelente resumo do empreendimento filosófico tradicional é dado por Rorty nesse trecho de A Filosofia e o Espelho da Natureza, quando explica o próprio título do seu trabalho: "São mais as imagens do que as proposições, mais as metáforas do que as afirmações, que determinam a maior parte de nossas convicções filosóficas. A imagem que retém cativa a filosofia tradicional é a da mente como um grande espelho, que contém várias representações - umas precisas, outras não - e que pode ser estudado por meio de métodos puros, não empíricos. Sem a noção da mente como espelho, a noção do conhecimento como exatidão da representação não se teria sugerido a si mesma. Sem esta última noção, a estratégia comum a Descartes e Kant - obter representações mais exatas mediante a inspeção, reparação e polimento do espelho, por assim dizer - não teria feito sentido. Sem esta estratégia em mente, as pretensões recentes de que a filosofia poderia consistir na 'análise conceptual', ou na 'análise fenomenológica', ou na 'explicação dos significados', ou no exame da 'lógica da nossa linguagem', ou da 'estrutura da actividade constitutiva da consciência', não teriam feito sentido" (Rorty 1988, p. 21).

\footnotetext{
${ }^{6}$ Essa visão aproxima o neopragmatismo rortyano de concepções de verdade como a de Habermas, calcada na noção de razão comunicativa e de condições ideais de fala. Os dois autores são aqui tributários de Charles Peirce, um dos expoentes da tradição pragmática clássica. São muitas, porém, as diferenças entre as perspectivas habermasianas e as do neopragmatismo, às quais faço referência mais à frente. Para citar já uma: não há referência às
}

instalada na tradição filosófica do século XX, inclusive no interior da filosofia analítica anglo-saxã, nicho no qual se formou o próprio Rorty; para ele,

\begin{abstract}
a filosofia 'analítica' é mais uma variante da filosofia kantiana, uma variante marcada principalmente pela consideração da representação como mais linguística do que mental, e da filosofia da linguagem, em detrimento da crítica transcendental ou da psicologia, como a disciplina que exibe os 'fundamentos do conhecimento'. Esta tônica na linguagem [...] não altera a essência da problemática cartesiano-kantiana, e não confere verdadeiramente uma nova imagem de si mesma à filosofia. Porque a filosofia analítica ainda está empenhada na construção de umquadro permanente e neutro para o inquérito e, por conseguinte, para o resto da cultura (idem, p. 18-19) $)^{5}$.
\end{abstract}

$\mathrm{Na}$ visão rortyana, o projeto alternativo ao que foi descrito começa a emergir, paulatinamente, a partir de William James e Nietzsche, ganhando fôlego com Wittgenstein, Heiddeger e Dewey (idem, p. 16-19). Nesses autores o que se delineia não é apenas uma crítica corretiva ou uma mera oposição à autoimagem tradicional assinalada, mas a proposta do seu completo abandono, esvaziando-se a própria ideia de que uma cultura necessita de fundamentos e de que caberia à filosofia fornecê-los, na qualidade de teoria geral da representação. Mais exatamente, o que se cristaliza, com os autores referidos, é a construção de novos e inéditos "mapas" a respeito das atividades humanas, os quais constituem vocabulários inteiramente diferentes sobre os problemas intelectuais; nos termos de Rorty, o que esses escritores fazem-nos vislumbrar é

a possibilidade de uma forma de vida intelectual, na qual o vocabulário da reflexãofilosófica herdado do século dezessete pareceria tão despropositado quanto o vocabulário filosófico do século treze para o iluminismo (idem, p. 17).

Mas quais os conteúdos desses novos mapas? Quais as peças centrais desses novos vocabulários? Uma forma possível de aproximar-se desses novos referenciais é apresentar os principais traços que, consoante Rorty, caracterizariam uma cultura que houvesse logrado libertar-se da tutela da filosofia tradicional (Rorty 1982, p. 40-46).

Em uma cultura desse tipo não existiria a crença de que temos, ou devemos ter, no nível mais profundo do nosso ser, um critério que nos ateste que estamos tocando a verdade. Em um ambiente cultural com esse perfil estaria banida a própria ideia de alcançar a realidade tal como ela é - vista como algo objetivo e independente da história e da cultura - como meta de nossos esforços para assegurarmo-nos de que possuímos cognição de algo ou verdade ética sobre qualquer coisa. Não que Rorty rejeite a ideia de conhecimento ou de verdade ética, mas os critérios de acessibilidade e a forma de pensar essas noções são profundamente modificados.

Na visão de Rorty, herdada, ao seu juízo, do pragmatismo clássico, a verdade representa simplesmente aquilo que se revela útil enquanto objeto de crença (Rorty 1993, p. 111). Nesse sentido, toma-se o consenso emergente no seio de uma comunidade como padrão relevante para a verdade ${ }^{6}$, tornando-se prescindível a ideia de uma relação de correspondência com algo que transcende as práticas humanas ou históricas bem como, naturalmente, a aferição do que nos torna hábeis a estabelecer tal relação. O que justifica uma pretensão materializa-se na esfera da prática e da ação, mais do que no plano da contemplação ou da teoria, tornando-se muito mais um "fenômeno social" do que "uma transação entre o 'sujeito cognoscente' e a 'realidade"” (Rorty 1982, p. $234 ; 1988$, p. 19) ${ }^{7}$.

Nessa óptica, o desejo de objetividade é retido, mas não mais como um impulso para escapar à história ou à nossa circunstância (Rorty 1982, p. 236). Para Rorty, esse impulso para ir além da historicidade e ancorar nossas convic- 
ideias de incondicionalidade e universalidade na reflexão de Rorty, ao contrário do que se verifica na estratégia habermasiana. A discussão por Habermas do pragmatismo e da obra de Rorty constitui um tópico central do seu livro Verdade e Justificação (Habermas 2004).

${ }^{7}$ É nesse contexto que se torna inteligível a leitura pragmática que Rorty propõe acerca do fenômeno da investigação: "não existem constrangimentos à investigação salvo os conversacionais nenhumas restrições gerais derivadas da natureza dos objetos, ou da mente, ou da linguagem, mas apenas as restrições particulares fornecidas pelas observações dos nossos companheiros investigadores" (Rorty 1982, p. 236-237).

\footnotetext{
${ }^{8}$ Essa crítica rortyana também abarca a filosofia empírica ou positivista, emergente com a revolução científica dos séculos XVI e XVII, que tem por modelo de acesso à realidade objetiva os métodos da ciência natural. Ver, nesse sentido, Rorty (idem, p. 1517).
}

ções éticas ou pretensões cognitivas em bases mais duradouras atravessa de longa data a tradição da Filosofia. Para exemplificar e criticar essa atitude, são várias as estratégias do autor em foco. Uma delas consiste em estilizar ou modelar personagens ou narrativas filosóficas que se nutrem das expectativas de transcendência.

Tomem-se, como ilustração do ponto, os seus tipos de "platônico" e "kantiano". Segundo Rorty, o "platônico" busca ser obrigado não apenas pelas normas "do seu tempo, mas pela natureza anistórica e inumana da própria realidade" (idem, p. 236). A postulação por Platão de um mundo das formas ou das ideias, a esfera superior do inteligível contraposta à esfera ordinária do sensível, destina-se a materializar o lugar dos novos objetos privilegiados ou puros, exatamente aqueles a que as "proposições consideradas como valiosas" devem corresponder. O "kantiano", por sua vez, busca princípios ou categorias puras apriorísticas, os quais lhe assegurarão o acesso seguro às essências do conhecimento, da moralidade, da representação, da racionalidade, etc. (ibidem). Trata-se em ambos os casos de "escapar ao vocabulário e às práticas do nosso próprio tempo e encontrar algo anistórica e necessário a que nos agarrarmos" (ibidem). Ao contrário, uma cultura diversa da tradicional não abrigaria expectativas de utilizar uma linguagem que se confundisse com a própria realidade. Nesse sentido, não emergiria ali a necessidade de nenhum ponto de Arquimedes anistórico (idem, p. 43) ${ }^{8}$.

Diversamente, objetividade aparece, no novo paradigma proposto, como a determinação de construir o "maior acordo intersubjetivo possível" (Rorty 1993, p. 111), sendo a natureza de tais acordos sempre provisórios, uma vez que a justificação alcançada é sempre contingente frente às informações disponíveis. Novas hipóteses, novos dados ou simplesmente novas maneiras de ver a questão, as quais desenham quadros inéditos de referência, no presente sequer imaginados, irão fazer com que a conversação sobre a verdade prossiga, o que seria assumido com naturalidade em uma cultura do tipo aqui enfocado. Para Rorty, portanto, falar em conhecimento e verdade equivale tão somente a fazer um "um elogio [...] às crenças que consideramos estar tão bem justificadas que, no momento, não é necessária justificação adicional" (idem, p. 113).

Outro traço relevante dessa cultura intelectual liberada seria o fato de levar-se a sério a ubiquidade da linguagem; ou seja, não seria motivo de estranhamento o fato de que jamais posso esperar estar diante da realidade, salvo a partir de descrições específicas ou narrações particulares (Rorty 1982, p. 42). Mas essa linguagem também não seria, nesse modo de ver as coisas, sinal ou signo de algo mais profundo e remoto. Assumir a ubiquidade assinalada, ao contrário, levaria a aquiescer que não foram produtivas as inúmeras tentativas de procurar algo que a fundamente ou algo de que ela, a linguagem, seja a expressão, ou mesmo de buscar aquilo a que ela deve se adequar (idem, p. 21).

Trata-se, aqui, ainda uma vez, de evidenciar a impossibilidade de acesso ao absoluto, isto é, o insucesso do modo platônico de pensar a reflexão filosófica. Nos termos do autor em foco,

A ubiquidade da linguagem é uma questão da linguagem a mover-se para os vazios deixados pelo fracasso de todos os vários candidatos à posição de "pontos de partida naturais' do pensamento, pontos de partida que [...] [seriam] primeiros e independentes da maneira como certas culturas falam ou falaram (os candidatos a esses pontos de partida incluem ideias claras e distintas, dados sensoriais, categorias do entendimento puro, estruturas de consciência pré-linguística e semelhantes) (ibidem). 
Uma forma de contrastar o modo tradicional de reflexão filosófica com a proposta que Rorty avança é, portanto, distinguir entre os que imaginam a possibilidade de discernir pontos de partida naturais para o pensamento daqueles que sustentam que o exercício da Filosofia compreende unicamente a comparação e o contraste entre diversas tradições culturais (idem, p. 39).

A visão que herdamos estimula-nos a pensar que "muito no fundo por debaixo de todos os textos, existe alguma coisa que não é apenas mais um texto", mas que, diferentemente, cristalizaria esse ponto de Arquimedes diante do qual "vários textos estão a tentar ser 'adequados"” (ibidem). Essa é a crença descartada pela leitura que Rorty faz do pragmatismo. Não há como testar de fora a adequação dos diferentes vocabulários e culturas porque não há como assumir um ponto de vista alheio ou externo aos vários vocabulários e culturas. Diferentemente, o exercício crítico em uma cultura intelectual renovada, ao juízo de Rorty, consistiria em apostar que "no processo de jogar vocabulários e culturas uns contra os outros, produzimos novas e melhores maneiras de falar e de agir -melhores não por referência a um padrão previamente conhecido, mas melhores apenas no sentido em que vêm a parecer claramente melhores do que as precedentes" (ibidem). É, portanto, através desses jogos recorrentes de contrastes e comparações que se tornam possíveis a expansão, clarificação e aperfeiçoamento dos artefatos simbólicos de uma cultura, bem como a invenção de novos aparatos, encontrando-se nessa operação intelectual o cerne do trabalho filosófico pós-metafísico (idem, p. 41; 1998, p. 91, nota 8).

Sendo fiel ao anti-representacionismo, herdado, talvez, do último Wittgenstein, no lugar de pensar os vocabulários como representantes, mais ou menos acurados, de como as coisas realmente são ou da realidade intrínseca das coisas, Rorty convida-nos a enxergar os vocabulários como ferramentas, construídas e empregadas pelos homens diante do mundo com que se defrontam. Nesse sentido, vocabulários fornecem-nos crenças e modos de lidar com o ambiente em que nos inserimos. A diferença entre vocabulários vem a ser, por conseguinte, os respectivos graus de utilidade e adequação que as crenças $e$ hábitos de ação a eles vinculados demonstram no enfrentamento cotidiano das nossas vidas (Brandom 2000, p. xiv). Aqui importa salientar a exata relação que, segundo Rorty, mantemos com o mundo natural e que projeta implicações sobre o ponto em questão. Na interpretação sustentada por Brandom (idem, p. xv), nessa matéria combinam-se, de modo criativo e até certo ponto irônico, as facetas historicista e naturalista do autor - tributário aqui de Darwin - e uma distinção kantiana acolhida por Rorty.

Trata-se de sustentar que a realidade que nos envolve pode no máximo ter efeitos causais no processo formativo de crenças humanas, mas jamais pode justificá-las; na síntese rortyana, o mundo está diante de nós, mas não a verdade:

Dizer que o mundo está diante de nós, que não é uma criação nossa, quer dizer, tal como o senso comum, que a maior parte das coisas no espaço e no tempo são efeitos de causas que não incluem os estados mentais do ser humano. Dizer que a verdade não está diante de nós é simplesmente dizer que onde não há frases não há verdade, que as frases são elementos das linguagens humanas e que as linguagens humanas são criações do homem. A verdade não pode estar diante de nós - não pode existir independente da mente humana - porque as frases não podem existir dessa maneiraou estar diante de nós dessa maneira. O mundo está diante de nós, mas as descrições do mundonão. Só as descrições do mundo podem ser verdadeiras ou falsas; o mundo por si próprio - sem auxílio das atividades descritivas dos seres humanos - não pode (Rorty 1992, p. 25).

Segundo Brandom (2000), Rorty aqui está fielmente acompanhando Kant na sua firme distinção entre questões de causação e questões de justificação, 
embora empregue essa ferramenta para dar combate à tradição epistemológica kantiana. É em virtude dessa distinção que encontramos, de forma recorrente nos textos de Rorty, o descarte da ideia de "tocar o fundo" ou de ancorar as pretensões cognitivas ou éticas em realidades anistórica ou extra-humanas, as quais, por conta da noção de representação, assumiriam, na reflexão tradicional, o papel de modelos frente as quais nossas crenças devem estar adequadas. Para Rorty, todas essas imagens constituem um vestígio religioso e completar o projeto iluminista requer sua superação (Rorty 1988, p. 16; Brandom 2000, p. xiv-xv).

\section{As ideias políticas de Rorty}

Passa-se agora a explorar os aspectos mais propriamente políticos da obra de Rorty. $\mathrm{O}$ foco, na presente seção, recai em uma ideia-chave desse autor, a saber, sua proposta de reconstrução de uma política democrática (Rorty 2005b, p. 103-162), a qual permite visitar uma série de questões relevantes para a reflexão político-normativa; essa política democrática, contemporaneamente, encontraria seu norte essencial na tentativa de estabelecer uma comunidade includente em nível planetário (idem, p. 104). Para o autor em foco, tratase de aprofundar, detalhar e defender a noção referida, livrando-a, contudo, de premissas metafísicas, antigas e recentes, explícita ou implicitamente ligadas à autoimagem tradicional da filosofia antes examinada.

Na reflexão progressista tradicional, herdeira da razão iluminista, três pressupostos seriam salientes: (i) a aposta na existência de um desejo universal pela verdade; (ii) a ideia de que a verdade é a correspondência com a realidade e (iii) a noção de que esta última possui uma estrutura intrínseca. Para Rorty, o conjunto das premissas se articularia da seguinte forma: sendo a verdade uma só, "o interesse humano pela verdade oferece o motivo para criar uma comunidade includente" (ibidem). Assim, o avanço e a disseminação das descobertas sobre a verdade - a ampliação do terreno comum partilhado - torna as sociedades mais tolerantes e includentes. Nessa linha, "a ascensão de sociedades relativamente democráticas e tolerantes, há alguns séculos, é atribuída à crescente racionalidade dos tempos modernos", compreendendo-se racionalidade como "o emprego de uma faculdade inata orientada para a verdade" (idem, p. 104-105).

Para Rorty, um primeiro movimento para dar novas cores à ideia de uma política democrática requer a substituição da noção de verdade pela de justificação. O motivo básico para isso é simples: a verdade, ao contrário da justificação, não é reconhecível e, portanto, não é um objetivo prático. Como argumenta Rorty, a certa altura de um debate, pode-se estar razoavelmente seguro que não existem mais objeções sérias a uma dada crença ou convicção. Tem-se, então, junto com os outros participantes da discussão, como mobilizar-se em torno da sustentação de certa proposta ou política, objeto de acordo intersubjetivo. Com o tempo, naturalmente, novas questões vão surgir, trazidas por distintos enfoques ou maneiras de pensar, o que indica o caráter provisório de qualquer justificativa. Isso significa simplesmente que não há convergência final, incondicionalidade ou ponto de chegada peremptório para a discussão

9 "O problema com a ideia de convergência ao fim da investigação [...] é que é difícil imaginar um tempo no qual seria desejável parar de desenvolver novas teori(idem, p. 105-107) ${ }^{9}$. Essa conclusão coaduna-se perfeitamente com a justificação, mas não com a verdade. Em uma sociedade democrática, essa dinâmica transformadora dos consensos alcançados é tão somente o resultado das disputas e indagações permanentes que são constitutivas da sua própria realidade pluralista. 
as e novos vocabulários" (Rorty 2005b, p. 116, nota 15).

${ }^{10}$ Rorty acredita que simplesmente inexiste a possibilidade de "nos garantirmos contra o risco de ter crenças que possam se mostrar injustificáveis perante alguma audiência futura" (Rorty 2005b, p. 114).

\footnotetext{
${ }^{11}$ Ver, sobre o ponto, o volume Filosofia, Racionalidade e Democracia organizado por Crisóstomo de Souza (2005).
}

Um modo interessante de ver esse ponto é introduzido pelas noções de audiências presentes e futuras e pelo uso acautelatório da noção de verdade. Para Rorty, a única distinção entre verdade e justificação que, de um ponto de vista pragmático, faz sentido (ou seja, produz diferença na prática), é quando utiliza-se o primeiro dos termos para advertir acerca de um tipo de perigo. Trata-se de lembrar às audiências presentes, aos companheiros de discussão, agora satisfeitos com certas conclusões alcançadas,

\begin{abstract}
que pode haver objeções (levantadas a partir da descoberta de novos dados, ou de hipóteses explicativas mais engenhosas, ou de mudança no vocabulário utilizado para descrever os objetos em discussão) que ainda não ocorreram a ninguém. Esse tipo de gesto, na direção de um futuro imprevisível é feito, por exemplo, quando dizemos que nossas atuais crenças morais e científicas podem vir a parecer tão primitivas a nossos descendentes remotos quanto a dos antigos gregos nos parecem hoje (idem, p. 112).
\end{abstract}

Excetuando esse uso acautelatório (e essencialmente negativo), Rorty não enxerga sentido nesse contraste nem na pergunta sobre se a justificação conduz à verdade. A justificação somente torna os que dela compartilham menos inseguros quanto à possibilidade de virem a ser refutados. Diferentemente, afirmar o nexo entre justificação e verdade equivaleria a transitar do condicionado ao incondicionado e a sustentar uma predição empírica completamente desarrazoada, a saber, que se pode estar, desde já, certo da manutenção das crenças correntes frente aos potencialmente infinitos contextos e audiências, presentes e futuros (idem, p. 131; 2005c, p. 215-216) ${ }^{10}$.

A justificação é, em Rorty, consequentemente, necessariamente local, contextual e condicionada, não podendo pretender uma "objetividade" que vá além desses parâmetros; quando se aceita a ideia de uma cultura intelectual renovada, nos termos esboçados na seção anterior, desaparecem as condições de sustentar a validade ou superioridade tout court de um argumento ou proposição, uma vez que

\begin{abstract}
todas as razões são razões para determinadas pessoas, que são limitadas (como as pessoas sempre são) por condições espaciais, temporais e sociais. Pensar de outra maneira é pressupor a existência de uma ordem natural de razões, da qual nossos argumentos, com sorte, aproximar-se-ão mais e mais. A ideia de tal ordem é apenas uma relíquia da ideia de que a verdade consiste na correspondência com a natureza intrínseca das coisas, uma natureza que de algum modo precede e subjaz todos os vocabulários descritivos. A ordem natural de razões é, para os argumentos, o que a natureza intrínseca da realidade é para as sentenças (Rorty 2005c, p. 223).
\end{abstract}

O choque de Rorty com visões como a do pensador alemão Jürgen Habermas - calcadas em uma aposta no caráter universalista dos pressupostos idealizantes do discurso, apreensíveis pela razão prática - é patente. Conquanto haja acordo no que concerne à necessidade de socializar e tornar linguística a noção de razão, transitando para a ideia habermasiana de razão comunicativa, não há, para Rorty, como conciliar sua postura com os aspectos convergentistas e tributários da ideia de incondicionalidade que ele identifica naquele autor. Os efeitos universalizantes e as pretensões de alegação de verdade que Habermas identifica nas proposições emergentes de condições ideais de comunicação parecem a Rorty apenas repor, em uma forma decerto extremamente sofisticada, os tradicionais postulados metafísicos com os quais deseja romper $^{11}$. Para ele, práticas de justificação orientadas para a verdade não transcendem convenções sociais; ao contrário, condições ideais de discurso supõem certas convenções sociais - convenções melhores e mais tolerantes do que as que qualquer sociedade democrática hoje apresenta (Rorty 2005b, p. 119-120).

Ainda no que toca à ética do discurso, cumpre assinalar que Rorty rejeita as hipóteses, caras a Habermas, de que a aptidão para respeitar convenções socia- 
${ }^{12}$ No ensaio The Priority of Democracy to Philosophy, Rorty (1991, p. 175-196) argumenta pela desnecessidade de fundamentos filosóficos para a democracia, arrolando John Rawls entre aqueles autores que nos mostraram como o experimento democrático pode ser pensado sem tais pressupostos. No entanto, as razões de Rorty e de Rawls para sustentar esse ponto são bem diferentes e isso não é enfatizado suficientemente no texto referido. A postura rortyana nesse assunto emerge como desdobramento do seu projeto filosófico anti-metafísico. Rawls não toma partido nessa disputa e apenas reconhece a impossibilidade dos "prefácios" filosóficos em função da inerradicável realidade pluralista que marca a sociedade ocidental moderna. Em suma, a conclusão de Rorty é em si própria filosófica, enquanto Rawls, buscando a construção de uma concepção política de justiça, opta por evitar ao máximo comprometimentos com doutrinas gerais (Rawls 1996, p. xl, p. 12-15, p. 133-172; 2003, p. 44-53).

${ }^{13}$ É justamente esse argumento que é desenvolvido com vigor por Álvaro de Vita no texto "Dois Tipos de Ceticismo Moral" (Vita 1999, p. 143-156). Sua crítica ao "interpretacionismo cultural" como método de avaliação éticonormativo levanta problemas importantes, apontando a inconsistência de pressupostos e perspectivas comumente aí encontrados como $(i)$ a ideia de incomensura- is dialógicas e democráticas possa decorrer de padrões universais de desenvolvimento filo ou ontogenético (idem, p. 138). Distintamente, em uma veia naturalista darwiniana, Rorty supõe que tudo que "a racionalidade significa - tudo o que separa os seres humanos de outras espécies de animais - é a habilidade de usar a linguagem e assim ter crenças e desejos" (ibidem). Embora Rorty concorde que o uso da linguagem implica justificação, esta não se dirige necessariamente a todos os outros organismos usuários de linguagem. Nos seus próprios termos, "não é qualquer usuário da linguagem que apareça no caminho que será tratado como membro de uma audiência competente" (ibidem). Em uma palavra, não posso extrair das estruturas associadas à ética do discurso um impulso de justificação universal, uma vez que "a filosofia da linguagem se esgota antes de alcançarmos [tais] imperativos morais" (ibidem).

É aqui que se reitera a noção rortyana de que a reflexão teórica não pode fundamentar a política, pois esta não tem necessidade de "prefácios" - no passado, religiosos ou transcendentes, hoje filosóficos (Rorty 1991, p. 175-179; Brandom 2000, p. xvi). Torna-se, portanto, estéril a busca filosófica por premissas neutras, de aceitabilidade geral, as quais nos habilitariam a inferir a obrigatoriedade racional da política democrática (Rorty 2005b, p. 157) ${ }^{12}$.

Naturalmente, vistos esses desenvolvimentos, não é difícil enxergar a crítica a que Rorty expõe-se ao trocar o conceito de verdade e/ou objetividade (na forma como ele é estruturado na ética do discurso, por exemplo) pela ideia de validade dependente de contexto; isso implica privar o agente de um referencial normativo hábil a sustentar determinadas obrigações morais para além de fronteiras ou comunidades particulares de justificação. A queda, então, em algum tipo de relativismo cultural aparece, para muitos, como decorrência imediata desse tipo de reflexão, com o efeito de solapar a defesa de valores caros à tradição democrática, fragilizando, por exemplo, o emprego de uma linguagem dos direitos humanos com pretensões universais ${ }^{13}$.

Seria equivocado desconhecer e/ou minimizar o desconforto que esse tipo de proposição causa. Sobremodo quando se atina com clareza para as várias implicações contidas no ponto de vista de Rorty, uma das quais vem a ser a impossibilidade de uma defesa dos valores liberais e democráticos com base em argumentos de racionalidade (mesmo na sua versão comunicativa) ${ }^{14}$.

Importa agora, no entanto, salientar que a postura política rortyana é simplesmente um desdobramento coerente do seu projeto filosófico e que ela não o impede de tomar uma atitude ativa em defesa da ampliação dos limites de uma comunidade democrática, ainda que por vias que não se confundem com a estratégia racionalista. A questão crucial, contudo, vem a ser a eficácia e a plausibilidade políticas do caminho proposto.

Nesse sentido, para Rorty, a impossibilidade de refutar outras concepções de mundo, no sentido de demonstrar ser a cultura liberal-democrática alicerçada em valores morais objetivamente superiores aos das visões concorrentes decorre de, não obstante estarmos plenamente convictos dessas crenças, só podermos justificá-las mediante um vocabulário específico, uma "parede" ou "cortina cultural" peculiar, construída por atos e pela imaginação humana em tempos e contextos determinados. Trata-se aqui de admitir a própria contingência da nossa comunidade democrática ${ }^{15}$. Esse passo, nas palavras de Rorty (1992, p. 82), "significaria abandonar a ideia de que o liberalismo pode ser justificado e os inimigos nazis ou marxistas [...] refutados, levando estes últimos a um muro argumentativo - forçando-os a admitir que a liberdade liberal tem um 'privilégio moral' de que os seus valores carecem. Do ponto de vista 
bilidade das culturas e (ii) de homogeneidade cultural de sociedades não-ocidentais. Vita assinala, adicionalmente, a controversa legitimidade normativa de consensos ou aquiescências, por parte dos próprios grupos prejudicados, a padrões sociais discriminatórios, uma vez que os mesmos são obtidos sob condições históricoestruturais distorcidas.

${ }^{14}$ Para Rorty (2005b, p. 132), os princípios liberais e democráticos definem apenas um jogo de linguagem política possível entre outros.

${ }^{15}$ Comunidades includentes basearam-se até o presente em desenvolvimentos humanos contingentes, "tais como a curiosidade inquieta (do tipo de gente excêntrica a que chamamos de 'intelectuais'); o desejo de casamentos para além das fronteiras, tribais ou de casta, produzido por obsessão erótica; a necessidade de comércio além de tais fronteiras, decorrente da falta de (por exemplo) sal ou ouro no próprio território; a posse de suficiente riqueza, segurança, educação e independência, de modo que o seu auto respeito não dependa mais de pertencer a uma comunidade excludente (de você não ser um infiel, um escravo ou uma mulher) etc." (Rorty 2005b, p. 144145). A ideia de contingência, contudo, aplica-se, de um modo mais geral, às noções de natureza e cultura, o que se expressa na interpretação que Rorty realiza da leitura deweyana de Hegel e Darwin: "Do ponto de vista de Dewey, [...] [o triunfo de uma espécie sobre a outra, no âmbito natural, ou a hegemonia de uma cultura sobre outras, no plano histórico], [...] [não] são indicativos de virtudes especiais, por exemplo, de um 'direito' a triunfar, de uma maior proximidade às metas da Natureza ou da História. Ambos são unicamente o resultado de concatenações de circunstâncias contingentes" (Rorty 1998, p. 88).

${ }^{16}$ A discussão encetada por Rorty (2005b, p. 110, nota 11) acerca do processo da independência norte-americana serve como um exemplo do ponto em discussão no texto. Trata-se de um argumento desenvolvido para apoiar as considerações de Cornelius que tenho vindo a defender, qualquer tentativa de empurrar o nosso adversário para uma parede fracassa desta maneira quando a parede contra a qual ele é empurrado passa a ser vista como mais um vocabulário, mais uma maneira de descrever coisas. A parede revela-se então como sendo uma cortina pintada, mais uma obra do homem, mais um pedaço de encenação cultural".

Essa "parede" neutra não existe porque, simplesmente, a verdade não está diante de nós (idem, p. 25), mas depende da formulação humana, necessariamente contextual e localizada. Para Rorty, a defesa de uma política democrática não deve, portanto, ser vista como um problema a ser resolvido no plano da racionalidade, mas como um embate a ser travado no terreno da imaginação, da empatia e dos sentimentos, por meio da construção persuasiva de imagens do homem e da sociedade centradas nos valores da tolerância e da cidadania democrática. A ampliação paulatina e persistente de uma comunidade comprometida com tais valores é a própria política democrática (Rorty 2005c, p. 124).

Esse é um ponto extremamente rico - e polêmico - na obra de Rorty, uma vez que aponta para a sua noção de progresso moral e para o papel da imaginação e da invenção no processo de transformação das sociedades ${ }^{16}$. Aqui também se abre a oportunidade de verificar o modo como Rorty discute a diferença entre culturas bem como a possibilidade de um diálogo entre elas.

Progresso moral, para Rorty, é mais o resultado "da ampliação das fronteiras da nossa imaginação" do que a consequência de obedecermos mais estritamente "a um imperativo independente de contexto" (Rorty 2005a, p. 226, nota 7). Trata-se de ampliar os limites da nossa comunidade de justificação, alargando o contingente dos que podem ser considerados aí inclusos, aos quais devemos lealdade ${ }^{17}$. Se considerarmos os polos confiança-obrigação como modos concorrentes de descrever o fenômeno moral fundamental - com Hume e Kant, respectivamente, como expressões fundamentais de cada uma das alternativas -, não há dúvida quanto à opção humeana de Rorty $(1998$, p. 105-124; 2005a, p. 92-94) ${ }^{18}$. Descartando a tese da impossibilidade do diálogo entre culturas - contraste, aliás, para ele não diferente em qualidade dos contrastes intra-societários de pontos de vista (Rorty 1993, p. 115) ${ }^{19}$-, Rorty entende, aqui em consonância com Hilary Putnam, que não há contradição entre essa perspectiva e o seu localismo, porquanto "dizer que devemos trabalhar com nossos olhos, que devemos ser etnocêntricos, é simplesmente dizer que crenças sugeridas por uma outra cultura devem ser testadas pela tentativa de tecê-las juntamente com crenças que já possuímos" (idem, p. 114). Em síntese, culturas não precisam ser pensadas enquanto "geometrias alternativas", com suas estruturas e axiomas irreconciliáveis (ibidem) ${ }^{20}$.

No entanto, a inteligibilidade de contextos culturais diversos não garante, pace Habermas, o acordo e nem mesmo a coexistência pacífica, uma vez que a troca profícua efetiva entre comunidades diversas é contingente ao grau em que se revele possível, na prática histórica, a construção de uma interface consensual de crenças e desejos (Rorty 1998, p. 121-124). A não consecução de uma aproximação maior entre sociedades devotadas a distintas lealdades não denota, porém, a irracionalidade de uma ou de ambas; é simplesmente a consequência da inexistência de um grau mínimo de compartilhamento ou de coincidência entre os estoques respectivos de crenças e desejos, obrigando, enquanto persistirem tais diferenças, a que as relações restrinjam-se à construção de um modus vivendi que não pode descartar o uso da força ${ }^{21}$.

No plano do diálogo intercultural, portanto, Rorty pensa que o compartilhamento amplo de determinados valores e crenças, em prol da sustentação de 
Castoriadis sobre a mudança histórica em face de críticas sustentadas por Habermas. A indagação fundamental seria a seguinte: como compreender processos históricos responsáveis por importantes mudanças sociais - no caso, a Revolução Norte-Americana e seus desdobramentos, um dos eventos mais caros à tradição liberal e democrática do Ocidente. Estaria esse processo embasado na afirmação progressiva de princípios universais validados pela razão ou em ações inventivas e produtoras de novas realidades que, paulatinamente, acabaram por solidificar-se no mundo factual? A resposta de Rorty aponta nitidamente na segunda direção: "os 'Pais Fundadores' [dos EUA] eram exatamente o tipo de demiurgos que Castoriadis tinha em mente quando falava na 'instituição do imaginário social'. O que agora imaginamos como 'o povo americano', uma comunidade de 'indivíduos que agem conscientemente, que são autônomos e que se realizam a si mesmos', devotados àqueles princípios, foi lentamente passando a existir, no curso do processo (muito gradual, pergunte-se a qualquer afro-americano) de erguer-se ao nível da imaginação dos 'Fundadores'. Assim, quando Habermas trata de criticar Castoriadis por não reconhecer 'qualquer razão para revolucionar uma sociedade reificada', exceto a decisão existencialista, 'porque nós o queremos', e quando pergunta 'quem poderia ser esse nós do querer radical', penso que seria justo responder que, em 1776, o 'nós' relevante não era o povo americano, mas Jefferson e alguns de seus amigos igualmente imaginosos". Em uma perspectiva diferente, mas ainda versando sobre o papel central da invenção e a imaginação na mudança social, ver o seminal estudo de Morgan (1989) sobre as revoluções inglesa e americana sugestivamente intitulado Inventing The People.

${ }^{17}$ Rorty enxerga o progresso moral como "a habilidade imaginativa das pessoas para identificarem-se com pessoas com as quais seus ancestrais não foram capazes de se identificar - pessoas de religiões diferentes, pessoas no outro lado do mundo, pessoas que patamares mínimos de justiça e tolerância, consubstancia uma das tarefas mais importantes a cargo da contemporaneidade; contudo, dificilmente esse acordo pode ser postulado já como pressuposto potencialmente no diálogo entre sociedades distintas, uma vez que se afastem, por exemplo, as pretensões universalistas da ética do discurso ${ }^{22}$. Para Rorty, nesses assuntos é preferível ser francamente etnocêntrico e confessar a impossibilidade de escapar-se à própria pele, descartando-se a fantasia de ter acesso a um fictício mundo da razão e da universalidade. Ademais, politicamente parece mais viável a utilização de um argumento honestamente estruturado a partir de um ponto de vista contingente - buscando enfatizar aspectos da própria experiência histórica que podem revelar-se valiosos quando estendidos ou traduzidos a outras culturas - do que apostar em postulações que aspiram encarnar, de algum modo "objetivo", as ideias de racionalidade ou da justiça, das quais outras sociedades seriam carentes, absoluta ou relativamente.

Feitas todas as contas, o que Rorty parece vislumbrar (e estimular) é que, livres da retórica racionalista, mulheres e homens poderiam mais facilmente aproximar-se uns dos outros (inclusive os que são diferentes e desafiam-se reciprocamente em termos dos seus específicos comprometimentos axiológi$\cos$ ), aqui ou em outras sociedades, como sujeitos possuidores de experiências ou história instrutivas e inspiradoras para relatar. O que é bem diferente de alguém que presume "fazer um melhor uso de uma capacidade humana universal” (Rorty 1988, p. 123-124).

Para Rorty, desse modo, a emancipação frente ao tipo de racionalismo tradicional constituiria uma aposta não só mais frutífera, mas, também, consonante com os ideais de um iluminismo levado as suas últimas consequências.

$\mathrm{Na}$ atualidade, uma agenda de pesquisa preocupada com a democracia e a tolerância e com os desafios postos a esses valores no mundo contemporâneo teria muito a ganhar visitando ou revisitando, de forma crítica, a contribuição rortyana, da qual se procurou aqui oferecer um breve panorama. 
parecem de início perturbadoramente diferentes de 'nós próprios"” (Rorty 2005a, p. 93).

18 "Acho que Hume pôs as coisas do modo certo quando disse que o contraste interessante é aquele entre pessoas com quem você pode sentir-se à vontade e pessoas com quem você não pode sentir-se à vontade - ou entre pessoas que você poderia imaginar ser e pessoas que você simplesmente não poderia imaginar ser. É por isso que penso na imaginação e nos sentimentos, mais que na razão (tomada como a capacidade de argumentar), como sendo as faculdades que mais contribuem para tornar possível o progresso moral" (idem, p. 94).

19 "Parte da força do ataque de Quine e Davidson à distinção entre o conceitual e o empírico é que a distinção entre diferentes culturas não difere em espécie da distinção entre teorias adotadas por membros de uma cultura singular. Os aborígines da Tasmânia e os colonizadores ingleses tiveram problemas de comunicação, mas este problema diferia apenas em extensão das dificuldades de comunicação experimentadas por Gladstone e Disraeli" (Rorty 2003, p. 115).

${ }^{20}$ Isso parece afastar Rorty de posturas associadas com a noção da incomensurabilidade de culturas.

21 " $O$ fato de que não existam jogos de linguagem mutuamente ininteligíveis não contribui muito, por si só, para mostrar que as disputas entre racistas e anti-racistas, democratas e fascistas podem ser decididas sem o recurso da força" (Rorty 2005b, p. 135$6)$.

${ }^{22}$ Uma ideia fundamental em Rorty - do ponto de vista dos temas aqui em foco - é que a universalidade de determinados valores, crenças e práticas precisa ser criada e não pressuposta. 
Sérgio Eduardo Ferraz (seferrazz@uol.com.br) é Doutor em Ciência Política pela Universidade de São Paulo (USP).

\section{Referências}

Brandom, R., ed. 2000. Rorty and His Critics. Oxford: Blackwell.

Crisóstomo de Souza, J., ed. 2005. Filosofia, racionalidade e democracia: os debates Rorty e Habermas. São Paulo: Unesp. Habermas, J., 2004. Verdade e Justificação. São Paulo: Loyola.

Morgan, E., 1989. Inventing The People: The rise of popular sovereignty in England and America. New York: W. W. Norton. Ramberg, B., 2007. Richard Rorty. In E.N. Zalta, ed. The Stanford Encyclopedia of Philosophy, "Rorty". Disponível em: http://plato.stanford.edu/entries/rorty/. Acesso em: 4.fev.2014.

Rawls, J., 1996. Political Liberalism. New York: Columbia University. 2003. Justiça como eqüidade: uma reformulação. São Paulo: M. Fontes.

Rorty, R., 1982. Conseqüências do Pragmatismo. Lisboa: Piaget. 1988. A Filosofia e o espelho da natureza. Lisboa: Dom Quixote.

1991. Objectivity, Relativism and Truth: Philosophical papers. V. 1. Cambridge (UK): Cambridge University. 1992. Contingência, ironia e solidariedade. Lisboa: Presença.

1993. Solidariedade ou objetividade? Novos Estudos, 36, pp. 109-121.

1998. Pragmatismo y Política. Barcelona: Paidós.

2005a. Para emancipar a nossa cultura. In J. Crisóstomo de Souza, ed. Filosofia, racionalidade e democracia: os debates Rorty e Habermas. São Paulo: Unesp.

. 2005b. Verdade, universalidade e política democrática. In J. Crisóstomo de Souza, ed. Filosofia, racionalidade e democracia: os debates Rorty e Habermas. São Paulo: Unesp.

2005c. Resposta a Jürgen Habermas. In J. Crisóstomo de Souza, ed. Filosofia, racionalidade e democracia: os debates Rorty e Habermas. São Paulo: Unesp.

Vita, A., 1999. Dois tipos de ceticismo moral. Novos Estudos, 55, pp. 143-156.

\section{ABSTRACT}

This article examines the philosophical thought of Richard Rorty and, in particular, its political dimension, outlining your unique and critical treatment of central themes in contemporary political theory. The objective of this paper is threefold: to draw attention to the fertility of the ideas of an author still little read in Brazil (i), noted the remarkable corrosive consequences of Rorty's approach to foundational assumptions and pretensions of important lines of thought in political theory (ii), and, in a more positive light, pointing the motivational potential of the writings of this author for thinking about new ways of justification of democracy (iii). Also point out, in this latter case, the limits to this kind of political-intellectual endeavor. The approach is to demarcate the general outlines of the philosophical project of the author, followed by a presentation of the more properly political topics of the work of Rorty. More specifically, the article explores Rorty's proposal to replace the notion of truth in justification, pointing up the consequences for claims of truth, objectivity and universalism, present in various lines of political theory. In this shaft, the article discusses the possible implications of Rorty's relativistic theses, coming up, by this route, the ideas of contingency, imagination and persuasion, which are a central core concept in thinking the author studied. A brief contrast to positions of authors like Habermas and Rawls, admired for Rorty, is outlined in order to clarify the specificity of Rorty's approach to politics. Examining these topics, the text results in a synthetic overview of Rorty's perspective about what comes to be, in the contemporaneity, a "democratic politics", free of "universalism" and "objectivity", in which gain decisive status issues of justification, tolerance and coexistence, necessarily thought of as contingent cultural constructs, within democratic societies and the global level (where there are political regimes with different and even contradictory political values). Thus, it seeks to provide the reader with an introduction and a sample of critical and constructive dimensions present in the work of Rorty, betting that research agendas concerned with the issue of ethical and normative justification of democracy and the limits of democratic tolerance to find this author a fruitful source of inspiration.

KEYWORDS: contemporary political theory; neo-pragmatism; democracy; justification; limits of tolerance 